\title{
Perineal Hernia after Laparoscopic Abdominoperineal Resection for Rectal Cancer: A Case Report and Review of the Literature
}

\author{
Zhenhua He ${ }^{1 *}$, Gaoyong Zhu' ${ }^{1}$, Sen Zhang' \\ ${ }^{1}$ Department of Gastrointestinal Surgery, He Zhou People's Hospital, Guangxi, China \\ ${ }^{2}$ Department of Colorectal Surgery, The First Affiliated Hospital, Guangxi Medical University, Guangxi, China \\ Email: ${ }^{\text {hzh0774@163.com }}$
}

Received 22 January 2015; accepted 13 February 2015; published 15 February 2015

Copyright (C) 2015 by authors and Scientific Research Publishing Inc.

This work is licensed under the Creative Commons Attribution International License (CC BY). http://creativecommons.org/licenses/by/4.0/

\section{(c) (i) Open Access}

\begin{abstract}
Perineal hernias are uncommon complications following laparoscopic abdominoperineal operations. There is still very little known about perineal hernia. There are only few case reports to describe the repair of postoperative hernias after laparoscopic abdominoperineal resection (APR) in the literature. Here we present one patient with a perineal hernia after laparoscopic abdominoperineal resection for rectal cancer. The surgical management with manual purse-string suture is described and discussed in this case report.
\end{abstract}

Keywords

Perineal Hernia, Laparoscopic, Abdominoperineal Resection

\section{Introduction}

Perineal hernia is defined as an intra-abdominal content protruding through the pelvic floor into the perineal region, and it is an infrequent complication after open abdominoperineal resection (APR). The reported incidence of patients requiring surgical correction may be between $0.62 \%$ and 3.5\% [1]-[3] following rectal resection procedures. However, the wide acceptance of laparoscopic procedures has resulted in more laparoscopic surgery being performed for colorectal cancers [4] [5]. Internal hernia through a mesenteric defect after laparoscopic colectomy has been occasionally described [6] [7]. Nonetheless, perineal hernia after laparoscopic APR (L-APR)

${ }^{*}$ Corresponding author.

How to cite this paper: He, Z.H., Zhu, G.Y. and Zhang, S. (2015) Perineal Hernia after Laparoscopic Abdominoperineal Resection for Rectal Cancer: A Case Report and Review of the Literature. Journal of Cancer Therapy, 6, $222-226$.

http://dx.doi.org/10.4236/jct.2015.62024 
is extremely rare. Here we report a case of a perineal hernia after L-APR for rectal cancer, and describe our successful repair of this hernia with transperineal manual purse-string suture.

\section{Case Report}

A 68-years-old woman underwent L-APR for rectal cancer and formation of colostomy. The patient was discharged home 16 days later with no postoperative complications and wounds intact. Pathological examination revealed a moderately differentiated tubular-papillary adenocarcinoma. The depth of tumor invasion was the deep muscularis propria, and no lymph nodal metastases were identified (0/19). And the tumor was classified as T2N0M0 according UICC stage [8]. About 6 months after L-APR, the patient complained of a reducible, slight painful perineal swelling, which made her uncomfortable. On examination, manual palpation of the perineal can suggest a perineal soft lump bulging in the subcutaneous (Figure 1(A)), especially on standing. When auscultation, bowel sounds could be heard. The patient wore a self-designed $\mathrm{T}$ hernia bandage to prevent enlargement of the perineal hernia. X-ray of the abdominal orthostatic and computed tomography (CT) showed the small intestine protruding through the pelvic floor into the perineal area (Figure 1(B) and Figure 1(C)).

After some discussion, the patient was placed in the jack-knife position under epidural anaesthesia, and a transperineal approach was used. The hernial sac was opened to reveal small bowel content and surgical exploration revealed there were intra-abdominal adhesions (Figure 2(A)). The hernia sac was dissected free; and the small bowel was returned to the pelvic cavity. Then three manual purse-string sutures were made with 4 - 0 PDS (polydiaxonone sutures) (Figure 2(B)). The thin, attenuated, residual perineal fascia was then closed with interrupted 2 - 0 sutures. The skin was closed with vertical mattress 4 - 0 reabsorbable sutures.

The operative time was 54 minutes with minimal blood loss, and there were no technical difficulties. Furthermore, the postoperative course was uneventful. Following repair, the patient remained asymptomatic with free of any sign of recurrent hernia for 6 months since her operation.

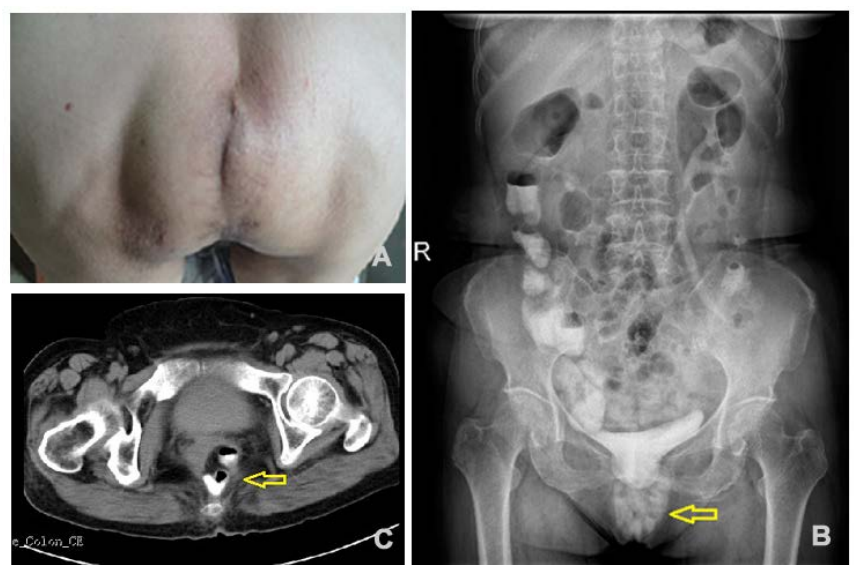

Figure 1. (A) Preoperative picture showing the perineal hernia defect; (B) X-ray of the abdominal orthostatic showing hernia; (C) Computed tomography (CT) scan showing the small bowel sliding through the pelvic floor into the perineal area.
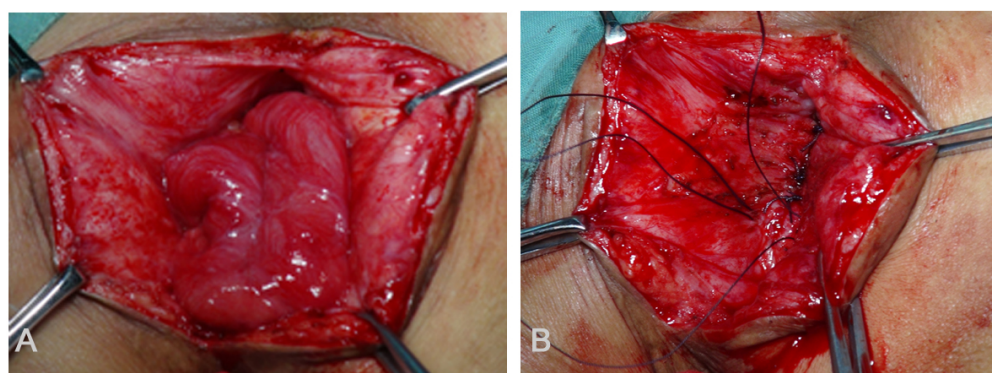

Figure 2. (A) Excision of the hernia sac revealed intra-abdominal adhesions; (B) Three manual purse-string sutures were made with reabsorbable sutures. 


\section{Discussion}

Perineal hernia still remains uncommon events. The incidence of perineal hernias after L-APR is extremely low and most publications appeared as case reports. Up to date only a total of six cases have been reported in the literature (Table 1 ).

Perineal hernias after APR may be the result of a complex interaction among various risk factors including the larger size of the female pelvis, previous hysterectomy, radiotherapy, coccygectomy, excessive length of small bowel mesentery, and perineal wound infection. These suggest that local factors have an important role in the development of these hernias.

Mesenteric or peritoneal reconstruction is not always performed with laparoscopic rectal surgery. This apparent higher risk observed after laparoscopic resections may be associated with some predisposing factors. First, the pelvic peritoneum is usually left open at the end of the laparoscopic procedure because the suture is commonly not possible in patients undergoing large resections after preoperative chemoradiotherapy leading to tissue fibrosis and retraction. Furthermore, as laparoscopic techniques exhibits a smaller potential for adherence formation when compared with laparotomy [9], there exists a favorable scenario predisposing some intestinal loops to slide toward the pelvis [2]. In this report, the patient was a woman with a large outlet of the pelvis though no previous gynecologic surgery. Beside, the pelvic peritoneum had not been closed during the L-APR approach. In addition, more extensive resections of the pelvic floor probably lead to perineal hernia. So, synchronous peritoneal repair should be recommended for selected patients undergoing L-APR, especially those at high risks of these types of hernia. Therefore, primary closure of the pelvic peritoneum and perineal wound and prevention of wound infection are important to avoid hernia formation.

Several methods of repair have been advocated for the treatment of perineal hernia, including transabdominal [10], perineal [11] and combined abdominoperineal approaches via various techniques including flaps or synthetic mesh. But there are obvious advantages and disadvantages to each of these repair techniques. Perineal mesh implantation has the simple advantage of being less morbidity and less invasive because the abdominal cavity is not entered. However, its main disadvantage is the limited exposure of the perineum, making any po-

Table 1. Perineal hernia after laparoscopic abdominoperineal resection (L-APR) for rectal cancer.

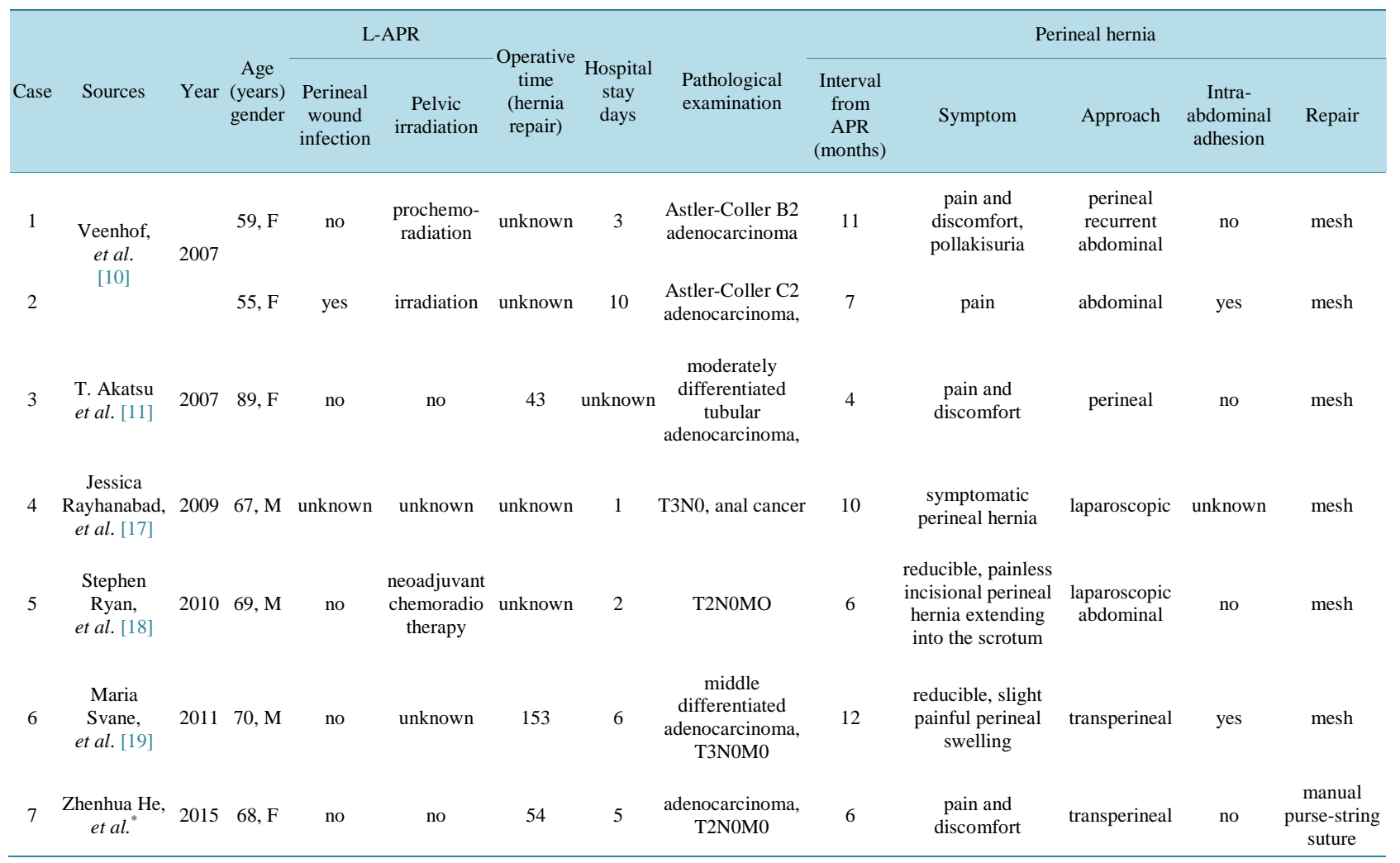

M: male; F: female. ${ }^{*}$ Current case. 
tential tumor recurrence difficult to exclude. The abdominal approach allows the surgeon to have better exposure for dissecting out sac contents like small bowel and to confirm the absence of abdominal recurrence. However, the abdominal approach is much more invasive and is accordingly being reserved for recurrent hernias. Laparoscopic access has the same advantages as abdominal approach and it combines the advantages of transabdominal approach and minimally invasive surgery as quick recovery time, faster bowel function and decreased trauma. Nevertheless, mesh fixation difficulties may lead to a high rate of hernia recurrence.

However, adequate fixation of meshes in perineal hernia repair can be difficult and it may be one reason why perineal hernia recurrence is frequent. Some studies describe the technique of transperineal mesh repair of recurrent symptomatic perineal hernia after previous transabdominal mesh repair [12]-[16]. So, from our personal experience, the perineal approach in prone position gives adequate exposure and the lack of adhesions after initial L-APR did not necessitate dissection of the small bowel out of the pelvic cavity. No additional surgical access is necessary, as the surplus skin overlying the hernia has to be resected anyway in case of significant bulging. Therefore the perineal approach is probably the first choice in uncomplicated perineal hernia.

In conclusion, symptomatic perineal hernias after L-APR require surgical repair. Many approaches have previously been described. However, the choice of the best approach must take into account individual characteristics and risks.

\section{Conflict of Interest Statement}

There are no conflicts of interest to report.

\section{References}

[1] So, J.B., Palmer, M.T. and Shellito, P.C. (1997) Postoperative Perineal Hernia. Diseases of the Colon \& Rectum, 40, 954-957. http://dx.doi.org/10.1007/BF02051204

[2] de Campos, F.G., Habr-Gama, A., Araujo, S.E., Sousa Jr., A.H., Nahas, C.R., Lupinacci, R.M., Nahas, S.C., Kiss, D.R. and Gama-Rodrigues, J. (2005) Incidence and Management of Perineal Hernia after Laparoscopic Proctectomy. Surgical Laparoscopy, Endoscopy \& Percutaneous Techniques, 15, 366-370. http://dx.doi.org/10.1097/01.sle.0000191592.93326.63

[3] Mjoli, M., Sloothaak, D.A., Buskens, C.J., Bemelman, W.A. and Tanis, P.J. (2012) Perineal Hernia Repair after Abdominoperineal Resection: A Pooled Analysis. Colorectal Disease, 14, e400-e406. http://dx.doi.org/10.1111/j.1463-1318.2012.02970.x

[4] Buunen, M., Veldkamp, R., Hop, W.C., Kuhry, E., Jeekel, J., Haglind, E., Pahlman, L., Cuesta, M.A., Msika, S., Morino, M., Lacy, A. and Bonjer, H.J. (2009) Survival after Laparoscopic Surgery versus Open Surgery for Colon Cancer: Long-Term Outcome of a Randomised Clinical Trial. The Lancet Oncology, 10, 44-52. http://dx.doi.org/10.1016/S1470-2045(08)70310-3

[5] Buchanan, G.N., Malik, A., Parvaiz, A., Sheffield, J.P. and Kennedy, R.H. (2008) Laparoscopic Resection for Colorectal Cancer. British Journal of Surgery, 95, 893-902. http://dx.doi.org/10.1002/bjs.6019

[6] Hosono, S., Ohtani, H., Arimoto, Y. and Kanamiya, Y. (2007) Internal Hernia with Strangulation through a Mesenteric Defect after Laparoscopy-Assisted Transverse Colectomy: Report of a Case. Surgery Today, 37, 330-334. http://dx.doi.org/10.1007/s00595-006-3405-4

[7] Jimi, S., Hotokezaka, M., Eto, T.A., Hidaka, H., Maehara, N., Matsumoto, K. and Chijiiwa, K. (2007) Internal Herniation through the Mesenteric Opening after Laparoscopy-Assisted Right Colectomy: Report of a Case. Surgical Laparoscopy, Endoscopy \& Percutaneous Techniques, 17, 339-341. http://dx.doi.org/10.1097/SLE.0b013e31806bf493

[8] Leslie, M.K.G., Sobin, H. and Wittekind, C. (2011) TNM Classification of Malignant Tumours. 7th Edition, WileyLiss, New York.

[9] Duepree, H.J., Senagore, A.J., Delaney, C.P. and Fazio, V.W. (2003) Does Means of Access Affect the Incidence of Small Bowel Obstruction and Ventral Hernia after Bowel Resection? Laparoscopy versus Laparotomy. Journal of the American College of Surgeons, 197, 177-181. http://dx.doi.org/10.1016/S1072-7515(03)00232-1

[10] Veenhof, A.A., van der Peet, D.L. and Cuesta, M.A. (2007) Perineal Hernia after Laparoscopic Abdominoperineal Resection for Rectal Cancer: Report of Two Cases. Diseases of the Colon \& Rectum, 50, 1271-1274. http://dx.doi.org/10.1007/10350-007-0214-9

[11] Akatsu, T., Murai, S., Kamiya, S., Kojima, K., Mizuhashi, Y., Hasegawa, H. and Kitagawa, Y. (2009) Perineal Hernia as a Rare Complication after Laparoscopic Abdominoperineal Resection: Report of a Case. Surgery Today, 39, 340343. http://dx.doi.org/10.1007/s00595-008-3851-2 
[12] Berendzen, J. and Copas Jr., P. (2011) Recurrent Perineal Hernia Repair: A Novel Approach. Hernia, 17, 141-144.

[13] Portilla, A.G., Martin, E., de Lecea, C.M., Gomez, C., Magrach, L., Cendoya, I. and Uzquiza, E. (2010) Recurrent Postoperative Perineal Hernia: Laparoscopic Redo Mesh Repair. Hernia, 14, 535-537. http://dx.doi.org/10.1007/s10029-009-0574-2

[14] Ruiz, D.E., Khaikin, M., Vivas, D., Newman, M. and Wexner, S.D. (2007) Multimedia Article. Recurrent Postoperative Perineal Hernia: Transperineal Redo Mesh Repair. Diseases of the Colon Rectum, 50, 1080-1081. http://dx.doi.org/10.1007/s10350-007-0232-7

[15] Corral, J., Yelamos, J., Hernandez-Espinosa, D., Monreal, Y., Mota, R., Arcas, I., Minano, A., Parrilla, P. and Vicente, V. (2005) Role of Lipopolysaccharide and Cecal Ligation and Puncture on Blood Coagulation and Inflammation in Sensitive and Resistant Mice Models. American Journal of Pathology, 166, 1089-1098. http://dx.doi.org/10.1016/S0002-9440(10)62329-2

[16] Dromain, C., Leboulleux, S., Auperin, A., Goere, D., Malka, D., Lumbroso, J., Schumberger, M., Sigal, R. and Elias, D. (2007) Staging of Peritoneal Carcinomatosis: Enhanced CT vs. PET/CT. Abdominal Imaging, 33, 87-93. http://dx.doi.org/10.1007/s00261-007-9211-7

[17] Rayhanabad, J., Sassani, P. and Abbas, M.A. (2009) Laparoscopic Repair of Perineal Hernia. Journal of the Society of Laparoendoscopic Surgeons, 13, 237-241.

[18] Ryan, S., Kavanagh, D.O. and Neary, P.C. (2010) Laparoscopic Repair of Postoperative Perineal Hernia. Case Reports in Medicine, 2010, Article ID: 126483.

[19] Svane, M. and Bulut, O. (2012) Perineal Hernia after Laparoscopic Abdominoperineal Resection—Reconstruction of the Pelvic Floor with a Biological Mesh $\left(\right.$ Permacol $\left.^{\mathrm{TM}}\right)$. International Journal of Colorectal Disease, 27, 543-544. http://dx.doi.org/10.1007/s00384-011-1253-1 
Scientific Research Publishing (SCIRP) is one of the largest Open Access journal publishers. It is currently publishing more than 200 open access, online, peer-reviewed journals covering a wide range of academic disciplines. SCIRP serves the worldwide academic communities and contributes to the progress and application of science with its publication.

Other selected journals from SCIRP are listed as below. Submit your manuscript to us via either submit@scirp.org or Online Submission Portal.
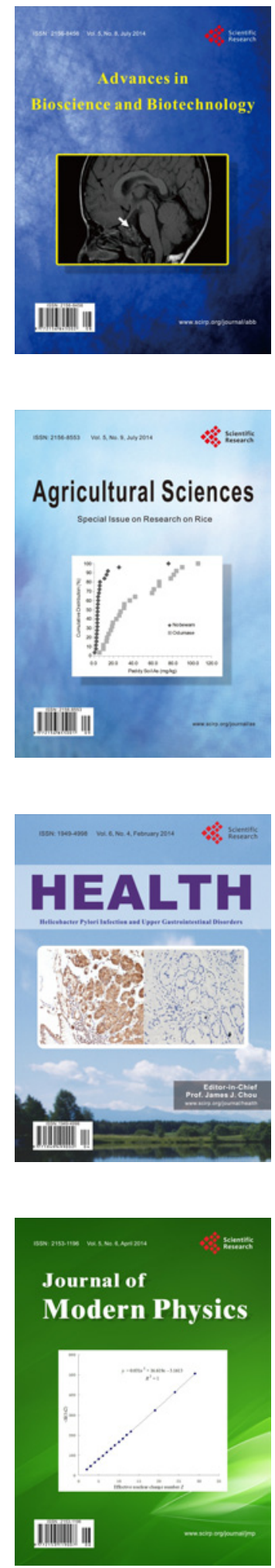
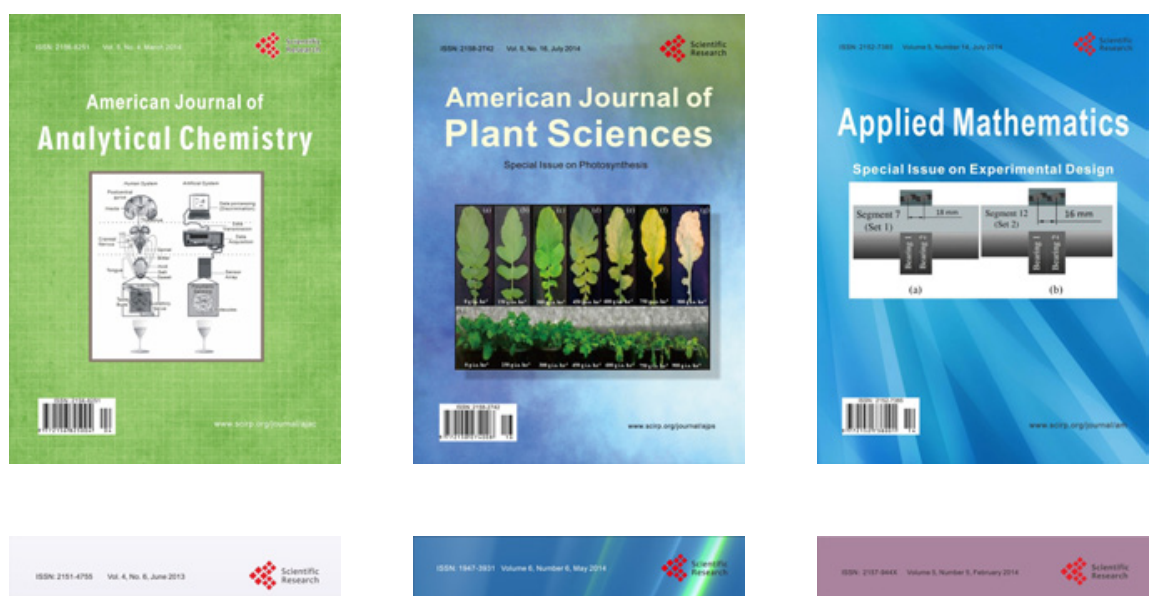

Creative Education
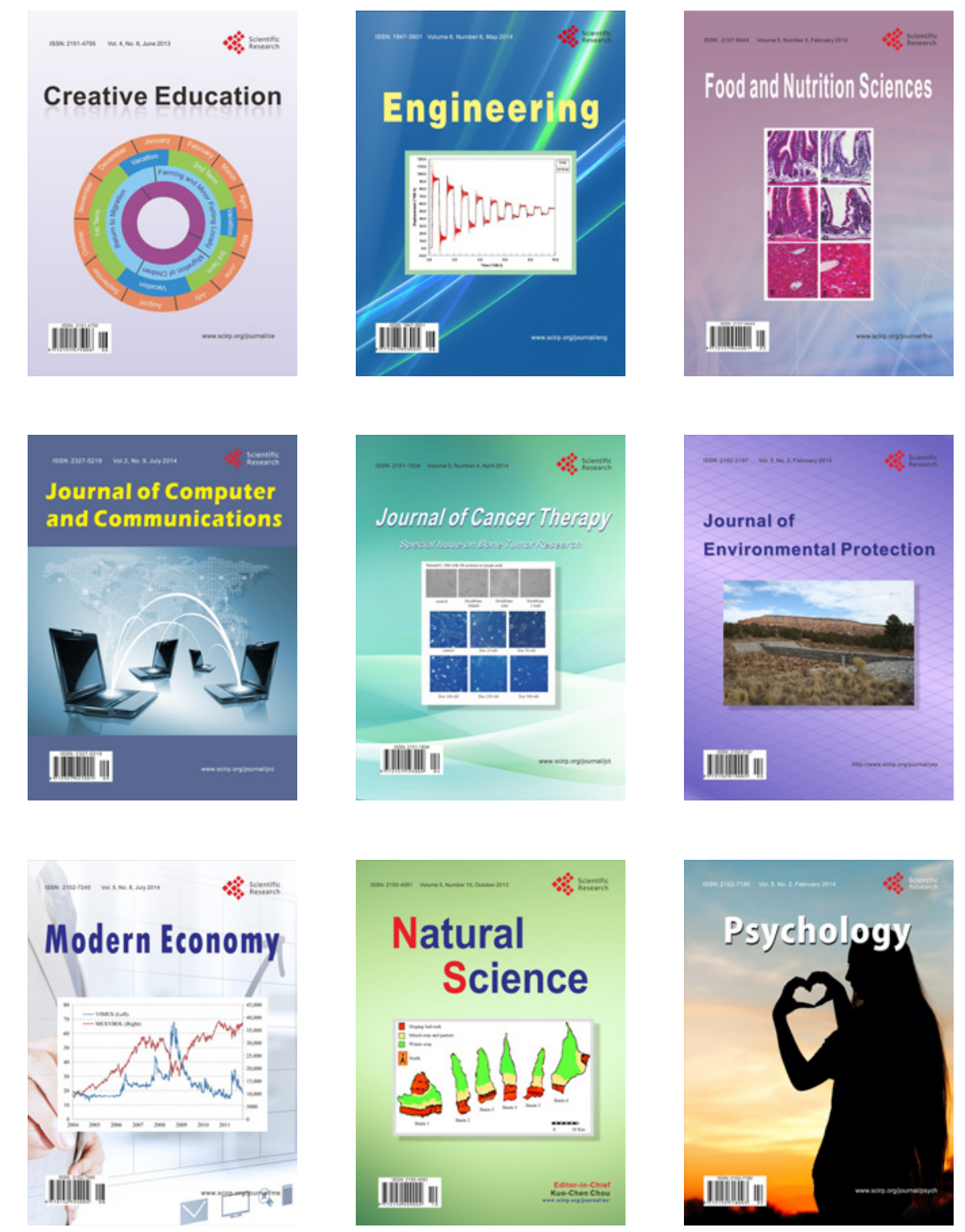